\title{
AC 2008-589: ADDRESSING FACULTY DEVELOPMENT AS A VITAL STEP IN TRANSFORMATIONAL CHANGE TO IMPROVE ENGINEERING TECHNOLOGY AND TECHNICIAN EDUCATION
}

Elaine Craft, Florence-Darlington Technical College

Joshua Phiri, Florence-Darlington Technical College

Principal Investigator, SCATE National Resource Center for Expanding Excellence in Technician Education and Instructor of Physics, Florence-Darlington Technical College

\section{Patressa Gardner, Florence-Darlington Technical College}

Project Manager, SCATE National Resource Center for Expanding Excellence in Technician Education and Business/Industry Liaison, Florence-Darlington Technical College 


\title{
Addressing Faculty Development as a Vital Step in Transformational Change to Improve Engineering Technology and Technician Education
}

\begin{abstract}
Staying current with technology and its applications has become an increasingly difficult challenge for Engineering Technology and other technician educators. Simultaneously, research is expanding what we know about how people learn. Faculty members therefore must be learners while they are teaching and learning to teach more effectively. Fortunately, The National Science Foundation and others are providing grant funding to make it possible for those with access to new knowledge and successful strategies to share information and effective practices with others through faculty development workshops. These learning opportunities are grant supported and thus are relatively inexpensive or even free of charge. Until now, there has been no good way for those providing faculty development events to notify their colleagues across the nation about these events. Likewise, faculty members have had no easy way to find out about professional development events of interest to them.
\end{abstract}

This disconnect, along with the realization that faculty development is critical for transformational change, led to the creation of a new faculty development event website, www.TeachingTechicians.org. www.TeachingTechnicians.org identifies, prioritizes, and makes visible National Science Foundation supported faculty development opportunities in advanced and emerging technologies, teaching methods, science, technology, engineering and mathematics. The site is searchable by multiple criteria such as location, date, subject, or target audience. Users will also be able to create an account that enables the system to generate a prompting e-mail alert whenever an event that matches their search criteria is posted. The site will also provide resources to help providers improve the quality of faculty development events.

Members of the academic community from all fields of advanced technological education and related science, technology, and mathematics disciplines are the website's target audience. Developed with funding support from the National Science Foundation (DUE \# 0602710), this website is becoming the one, central "go to" place for those offering faculty development and those seeking faculty development.

This website is being developed as a service to the nation by the South Carolina Advanced Technological Education (SCATE) Center of Excellence at Florence-Darlington Technical College, Florence, South Carolina. Increasing the quantity, quality, diversity of students entering engineering technology programs has been the vital mission and vision of the SCATE Center of Excellence since its inception in 1994. To accomplish this mission, the Center has developed research-based curriculum models that have produced significant improvements in retention, graduation rates, and industry partnerships for engineering technology programs. An unwavering focus on faculty development has been central to the development of SCATE models and their success. The highly rated SCATE curriculum has been adopted or adapted for use in technical programs by other schools and colleges around the country. Students benefit because learning that often appeared fragmented into various courses with no apparent interconnections has undergone multi-disciplinary integration that is now changing the culture of 
learning for first year engineering technology students. The new resource, www.TeachingTechnicians.org, will enable more teachers to learn about and implement new approaches such as the SCATE model to improve the nation's technological workforce. 